\title{
Methylphenidate Enhances the Abuse-Related Behavioral Effects of Nicotine in Rats: Intravenous Self-Administration, Drug Discrimination, and Locomotor Cross-Sensitization
}

\author{
Thomas E Wooters', Nichole M Neugebauer', Craig R Rush ${ }^{\mathbf{1 , 2 , 3}}$ and Michael T Bardo*,' \\ 'Department of Psychology, College of Arts and Sciences, University of Kentucky, Lexington, KY, USA; ${ }^{2}$ Department of Behavioral Science, College \\ of Medicine, University of Kentucky, Lexington, KY, USA; ${ }^{3}$ Department of Psychiatry, College of Medicine, University of Kentucky, Lexington, \\ KY, USA
}

\begin{abstract}
Stimulant drugs, including D-amphetamine, cocaine, and methylphenidate, increase cigarette smoking in controlled human laboratory experiments. Although the mechanism(s) underlying this effect are unknown, it is possible that stimulants may enhance directly the abuse-related effects of nicotine. In the present study, we characterized the behavioral pharmacological interactions between methylphenidate and nicotine in the intravenous self-administration, drug discrimination, and locomotor cross-sensitization procedures. Adult male Sprague-Dawley rats were trained to respond for intravenous nicotine $(0.01$ or $0.03 \mathrm{mg} / \mathrm{kg} /$ infusion) or sucrose, and the acute effects of methylphenidate $(1.25-10 \mathrm{mg} / \mathrm{kg})$ were determined; in addition, separate groups of rats were treated with methylphenidate $(2.5 \mathrm{mg} / \mathrm{kg})$ or saline before 12 consecutive nicotine $(0.03 \mathrm{mg} / \mathrm{kg} /$ infusion $)$ self-administration sessions. Next, the discriminative stimulus effects of nicotine $(0.03-0.3 \mathrm{mg} / \mathrm{kg})$ and methylphenidate $(1.25-10 \mathrm{mg} / \mathrm{kg})$, alone and in combination with a low nicotine dose $(0.056 \mathrm{mg} / \mathrm{kg})$, were tested in nicotine-trained rats. Finally, the locomotor effect of repeated methylphenidate $(2.5 \mathrm{mg} / \mathrm{kg})$ was tested in rats previously treated with nicotine $(0.2-0.8 \mathrm{mg} / \mathrm{kg})$. Results indicated that acute methylphenidate increased the rate of nicotine self-administration at doses that reduced sucrose-maintained responding; furthermore, tolerance to this effect was not apparent following repeated methylphenidate. Methylphenidate, while not substituting for nicotine alone, dose-dependently enhanced the discriminative stimulus effect of a low nicotine dose. In addition, repeated nicotine exposure promoted the development of locomotor sensitization to methylphenidate. Taken together with recent clinical findings, these results suggest that methylphenidate may enhance the abuse-related behavioral effects of nicotine, perhaps increasing vulnerability to tobacco dependence.
\end{abstract}

Neuropsychopharmacology (2008) 33, I I37-I | 48; doi:I 0. I 038/sj.npp. I 30 I477; published online 20 June 2007

Keywords: drug discrimination; locomotor activity; methylphenidate; nicotine; self-administration; sensitization

\section{INTRODUCTION}

Converging lines of evidence indicate that the use of stimulant drugs, including D-amphetamine and cocaine, is associated with tobacco cigarette smoking. Cigarette smoking is positively correlated with recent cocaine use among college students (Schorling et al, 1994), and drug abusers testing positive for recent cocaine use have elevated urinary levels of the nicotine metabolite cotinine (Roll et al, 1997). Results from controlled human laboratory experiments also indicate that acute administration of stimulant drugs can directly increase rates of spontaneous cigarette smoking. Relative to placebo, acute administration of oral

\footnotetext{
*Correspondence: Professor MT Bardo, Department of Psychology, College of Arts and Sciences, University of Kentucky, BBSRB, Room 253, Lexington, KY 40536-0509, USA, Tel: + I 859257 6456, Fax: + I 859257 3235, E-mail: mbardo@uky.edu Received 22 February 2007; revised 25 April 2007; accepted I4 May 2007
}

D-amphetamine or bupropion, or intranasal administration of cocaine, has been shown to dose-dependently increase cigarette smoking (Cousins et al, 2001; Henningfield and Griffiths, 1981; Roll et al, 1997). In addition, D-amphetamine has been shown to increase choice of cigarettes over money (Tidey et al, 2000) and can increase progressive-ratio (PR) break points maintained by cigarettes (Sigmon et al, 2003). Taken together, these results suggest that stimulant drugs can promote cigarette smoking in the natural environment, as well as in controlled laboratory settings, perhaps by augmenting the reinforcing efficacy of nicotine. However, since cigarette smoking involves pharmacologic and nonpharmacologic factors in addition to nicotine (Bardo et al, 1999; Fowler et al, 2003; Rose and Levin, 1991), other interpretations cannot be ruled out.

Although the exact mechanism(s) underlying stimulantinduced increases in cigarette smoking is yet to be elucidated, evidence from preclinical animal studies suggests that the interactive effect of nicotine and stimulants on mesolimbic dopamine function may be involved. In a 
microdialysis study using rats, coadministration of cocaine with nicotine was shown to produce an additive increase in extracellular dopamine levels in the nucleus accumbens (NAcc) relative to administration of nicotine alone (Gerasimov et al, 2000a,b). Similarly, behavioral studies have shown that administration of indirect dopamine agonists, such as monoamine oxidase inhibitors (which prevent intracellular metabolism of dopamine) or bupropion (a dopamine reuptake inhibitor), increase nicotine self-administration in rats (Guillem et al, 2005, 2006; Rauhut et al, 2003). Thus, it is possible that stimulant drugs increase nicotine self-administration, at least in part, by augmenting nicotine-induced increases in extracellular dopamine levels in the NAcc.

Similar to the effects observed with cocaine and amphetamine, a recent report by Rush et al (2005) found that methylphenidate also increased cigarette smoking in humans tested in a controlled laboratory setting. In that study, methylphenidate (5-40 mg) dose-dependently increased both the total number cigarettes smoked, as well as positive subjective ratings of cigarette smoking relative to placebo. Specificity of the methylphenidateinduced facilitation of cigarette smoking was also evident, as methylphenidate dose-dependently decreased food consumption (Rush et al, 2005). Based on these findings, the current study sought to determine if there is a direct pharmacologic interaction between methylphenidate and nicotine using rat models of drug abuse. First, we assessed the dose effect of acute methylphenidate pretreatment on nicotine self-administration and sucrosemaintained responding. Second, we determined the effect of repeated methylphenidate pretreatment on nicotine selfadministration. Third, we examined the discriminative stimulus effects of methylphenidate, both alone and in combination with a low nicotine dose, in rats trained to discriminate nicotine from saline. Finally, we examined the effect of repeated nicotine on subsequent methylphenidateinduced hyperactivity.

\section{MATERIALS AND METHODS}

\section{Subjects}

Adult male Sprague-Dawley rats (Harlan Industries Inc., Indianapolis, IN, USA), initially weighing 250-275 g, were used in all experiments. Rats used for operant conditioning experiments were housed individually in standard plastic cages, and rats used for the locomotor activity experiment were housed two per cage. For the self-administration and food-maintained responding experiments, rats were allocated 18-20 g of food per day (the daily food allotment for a given rat was held constant for the duration of each experiment). For the drug discrimination experiment, rats were provided sufficient food to maintain body weight at $\sim 350 \mathrm{~g}$. For the locomotor activity experiment, rats were provided $a d$ lib access to food. All rats had constant access to water in the home cage. Rats were housed in a temperature- and humidity-controlled colony set to a $14: 10$ light/dark cycle (lights on at 0600), and all experimental procedures were conducted during the light phase. Experimental protocols were in accordance with the NIH Guide for the Care and Use of Laboratory Animals (1996) and were approved by the Institutional Animal Care and Use Committee at the University of Kentucky.

\section{Apparatus}

The drug self-administration, sucrose-maintained responding, and drug discrimination experiments were conducted in operant conditioning chambers (ENV-008, Med Associates, St Albans, VT, USA). Each chamber was housed in a sound-attenuating enclosure (ENV-018M, Med Associates) and was connected to a personal computer via an interface (SG-502, Med Associates). A $5 \times 4.2 \mathrm{~cm}$ opening that allowed access to a recessed food tray was located on the front panel of the operant conditioning chamber. Two retractable metal response levers were mounted next to the food tray (one on each side) $7.3 \mathrm{~cm}$ above a metal-grid floor. A $28 \mathrm{~V}, 3-\mathrm{cm}$ diameter, white cue light was centered $6 \mathrm{~cm}$ above each response lever. For the drug self-administration experiments, an infusion pump (PHM-100, Med Associates) delivered drug infusions via a silastic tube attached to a swivel mounted on the outside of the back wall.

Locomotor activity was monitored with an automated Digiscan animal activity monitoring system (AccuScan Instruments, Columbus, $\mathrm{OH}$, USA). The system consisted of 12 clear Plexiglass chambers $(42 \times 42 \times 30 \mathrm{~cm})$ made opaque by attaching sheets of white plastic to each outer surface. Each chamber incorporated a horizontal $16 \times 16$ grid of photo beam sensors spaced $2.5 \mathrm{~cm}$ apart and $7.0 \mathrm{~cm}$ above the chamber floor. The activity monitors were interfaced to a personal computer operating Digipro System software (v. 1.40, AccuScan Instruments). Horizontal activity was measured as photo beam interruptions and expressed as distance traveled $(\mathrm{cm})$.

\section{Nicotine Self-Administration}

For nicotine self-administration, rats were first trained briefly to lever press for sucrose reinforcement $(45 \mathrm{mg}$ BioServ pellets) by pressing an active lever (lever designations were counterbalanced across rats) in the two-lever operant conditioning chamber under a fixed-ratio (FR) 1 schedule of reinforcement in 15-min daily sessions. Over the next six sessions, the response requirement was incremented to an FR5. Training was considered complete following two sessions of responding under the FR5 schedule.

Following completion of the initial pre-training period, rats underwent intravenous catheterization surgery. Briefly, rats were anesthetized with injections of ketamine $(60 \mathrm{mg} /$ $\mathrm{kg}$, i.p.) and xylazine $(8 \mathrm{mg} / \mathrm{kg}$, i.p.). The right jugular vein was then isolated, and one end of a silastic catheter was inserted. The other end of the catheter exited the skin and was secured to the skull by an acrylic head mount. During experimental sessions, a silastic leash protected by flexible metal tubing was used to attach the catheter to the drug infusion pump.

Nicotine self-administration commenced following a 5day surgical recovery period, and was based on the general method of Corrigall and Coen (1989), with some modifications. Rats were reintroduced to the operant conditioning chamber during daily 60-min sessions. Responses on the active lever (FR1) were recorded and resulted in an infusion 
of nicotine $(0.01$ or $0.03 \mathrm{mg} / \mathrm{kg} /$ infusion, delivered in a volume of $100 \mu \mathrm{l}$ over $5.9 \mathrm{~s}$ ); responses on the inactive lever were recorded but had no scheduled consequence. Completion of the FR requirement resulted in simultaneous activation of the infusion pump and the cue lights, which signaled a 20-s time-out (TO) period during which responding on either lever had no programmed consequence. Over the next six sessions, the FR1 schedule was gradually increased to a terminal FR5 20-s TO schedule. Rats were trained on the FR5 schedule until responding stabilized for three consecutive sessions according to the following criteria: (1) a minimum of 10 infusions per session, (2) less than $20 \%$ variability in the number of infusions earned, and (3) a minimum 2:1 active: inactive lever response ratio.

To assess the dose effect of methylphenidate on nicotine self-administration, separate groups of rats were pretreated with methylphenidate $(0,1.25,2.5,5$, or $10 \mathrm{mg} / \mathrm{kg}$, s.c.; random order within subjects) $10 \mathrm{~min}$ before a session in which the unit dose of nicotine was either $0.01 \mathrm{mg} / \mathrm{kg} /$ infusion $(n=7)$ or $0.03 \mathrm{mg} / \mathrm{kg} /$ infusion $(n=7)$. At least two maintenance sessions (no pretreatment) intervened between each pretreatment session in order to maintain stable nicotine self-administration behavior. To assess the effect of repeated methylphenidate on nicotine self-administration $(0.03 \mathrm{mg} / \mathrm{kg} /$ infusion $)$, separate groups of rats were pretreated 10 min before each of 12 consecutive sessions with methylphenidate $(2.5 \mathrm{mg} / \mathrm{kg}$, s.c.; $n=8)$ or saline $(n=6)$. Following drug pretreatment sessions, both groups of rats were pretreated with saline for three additional nicotine self-administration sessions.

\section{Sucrose-Maintained Responding}

In order to use procedures similar to the nicotine self-administration experiments, a separate group of rats $(n=8)$ was trained to lever press for sucrose reinforcement during daily $60-\mathrm{min}$ sessions under an FR5 20-s TO and was allocated the same amount of daily food as the nicotine self-administration rats; however, these rats did not undergo surgery. In addition, since sucrose reinforcement maintains higher response rates than nicotine, these rats were given 25 sucrose pellets in the home cage $15 \mathrm{~min}$ before each experimental session in an attempt to reduce response rates by partial satiation. Rats were monitored to ensure that all pellets were consumed before each session. Although insertion of a long TO is sometimes used to decrease food reinforcement rate (Paterson et al, 2003), we did not use this procedure because it can impose an artificial ceiling effect which would not be sensitive to potential increases in the rate of responding. Training continued until stable responding was obtained, defined as (1) a minimum of 10 pellets earned per session, (2) less than $20 \%$ variability in the number of pellets earned, and (3) a minimum 2:1 active: inactive lever response ratio. The effect of methylphenidate $(0,1.25,2.5,5$, or $10 \mathrm{mg} / \mathrm{kg}$, s.c.; random order within subjects) given 10 min before the sessions was then determined. At least two maintenance sessions (no pretreatment) intervened between each pretreatment session in order to maintain stable sucrose-maintained behavior.

\section{Nicotine Drug Discrimination}

Rats $(n=6)$ were trained initially to lever press for sucrose reinforcement under an FR1 schedule. The FR requirement for reinforcement was subsequently increased over several sessions to a terminal FR10. In order to enhance acquisition of the nicotine-saline discrimination, only one lever (the saline-appropriate lever; counterbalanced across rats) was presented during these initial sessions. Once rats responded for two sessions under the FR10 schedule, nicotine discrimination training began. In this phase, nicotine $(0.3 \mathrm{mg} / \mathrm{kg}$, s.c.) or saline was administered before each session. Ten minutes after nicotine or saline was administered, rats were placed in the operant conditioning chamber, and the cue lights were illuminated to signal the beginning of the session and they remained illuminated for the duration of the session. When nicotine was administered, the nicotine-appropriate lever was presented and the saline-appropriate lever was removed. When saline was administered, the saline-appropriate lever was presented and the nicotine-appropriate lever was removed. For half of the rats, the left lever was designated the nicotineappropriate lever and the right lever was designated the saline lever; the reverse was true for the remaining rats. Nicotine and saline were administered according to a double-alternation sequence (ie NNSSNN or SSNNSS, counterbalanced across rats) for eight consecutive sessions. Then, for the remainder of the study, both levers were presented each day, and responding on the injectionappropriate lever was reinforced according to the FR10 schedule; responses on the incorrect lever were recorded but had no programmed consequence. Training sessions were $15 \mathrm{~min}$ in duration. Training continued until the following criteria were met on eight consecutive sessions: (1) $\geqslant 85 \%$ of the total session responses occurred on the injection-appropriate lever and (2) first FR10 was completed on the injection-appropriate lever. Once these criteria were met, the test phase was initiated.

During the test phase, sessions were $3 \mathrm{~min}$ in length; on these sessions, completion of an FR10 on either lever was reinforced with sucrose. Each test session was separated by at least two 15-min training sessions in which saline and the nicotine training dose were administered once each (random order). Test sessions were conducted only if baseline performance during the intervening training sessions remained stable (ie $\geqslant 85 \%$ of the total session responses occurred on the injection-appropriate lever and the first FR10 was completed on the injection-appropriate lever). Two dependent measures were collected during test sessions: (1) percentage of total responses occurring on the nicotine-appropriate lever (calculated as the number of responses on the nicotine-appropriate lever divided by the total number of responses on either lever) and (2) rate of responding (calculated as the total number of responses on either lever divided by $180 \mathrm{~s}$ ). During test sessions, a dose-effect curve for nicotine (0.03, 0.056, 0.1, 0.17, and $.3 \mathrm{mg} / \mathrm{kg}$, s.c.; random order within subjects) was determined first, followed by determination of dose-effect curves for methylphenidate $(1.25,2.5,5$, and $10 \mathrm{mg} / \mathrm{kg}$, s.c.; random order within subjects) administered alone or in combination with a subthreshold nicotine dose $(0.056 \mathrm{mg} / \mathrm{kg})$. Each drug dose that was tested alone was administered $10 \mathrm{~min}$ 
before the test session; in the drug combination experiment, methylphenidate $(1.25,2.5,5$, and $10 \mathrm{mg} / \mathrm{kg}$, s.c.; random order within subjects) was administered $15 \mathrm{~min}$ before the session, and nicotine $(0.056 \mathrm{mg} / \mathrm{kg})$ was administered $10 \mathrm{~min}$ before the start of the session.

\section{Locomotor Effect of Methylphenidate in Nicotine-Sensitized Rats}

Rats were placed individually for $60 \mathrm{~min}$ in the locomotor activity apparatus for a single habituation day. Each rat was then assigned randomly to receive repeated injections of a single dose of nicotine $(0.2,0.4$, or $0.8 \mathrm{mg} / \mathrm{kg}$, s.c.) or saline. Nicotine or saline injections were administered for 10 consecutive days (days 1-10), beginning on the day following the habituation session. After each injection, rats were placed immediately in the activity monitors for $60 \mathrm{~min}$. Following the 10-day nicotine treatment period, rats remained in their home cages for a 14-day (days 11-24) drug-free period. Rats from each nicotine dose treatment group were then assigned randomly to receive challenge injections of methylphenidate $(2.5 \mathrm{mg} / \mathrm{kg})$ or saline immediately before placement in the activity monitors for $60 \mathrm{~min}$ for three consecutive sessions (days 25-27). The dependent measure was distance traveled $(\mathrm{cm})$.

\section{Drugs}

$S(-)$-nicotine ditartrate (Sigma-Aldrich, St Louis, MO) and methylphenidate $\mathrm{HCl}$ (Mallinckrodt, St Louis, MO) were prepared in $0.9 \% \mathrm{NaCl}$ (saline). Dilute $\mathrm{NaOH}$ was added to the nicotine solution until a $\mathrm{pH}$ of 7.4 was attained. The nicotine doses are expressed as the base weight and the methylphenidate doses are expressed as the salt weight.

\section{Statistical Analyses}

A one-way repeated-measures analysis of variance (ANOVA) (with dose as the within-subjects factor) was used to evaluate dose-effect curves in the acute nicotine self-administration, sucrose-maintained responding, and drug discrimination experiments. In cases where the dose effect attained statistical significance, Dunnett's post hoc tests were conducted to compare each dose to the corresponding saline control. Specifically, the dose effects of methylphenidate in rats selfadministering either 0.01 or $0.03 \mathrm{mg} / \mathrm{kg} /$ infusion unit doses of nicotine were compared to the effect of saline pretreatment within the same groups. In the repeated nicotine selfadministration and locomotor activity experiments, data were analyzed with mixed-factor ANOVA, with pretreatment dose serving as a between-subjects factor and session serving as a within-subjects factor. When data from experiments designed to test a priori hypotheses were analyzed, one-tailed tests were used. Where appropriate, the Newman-Keuls post hoc test was used to make multiple comparisons; in those instances, a conservative alpha level of $p \leqslant 0.01$ was used as the criteria for statistical significance to control for type I errors. In all other cases, $p \leqslant 0.05$ determined significance. In drug discrimination, the nicotine dose estimated to produce $50 \%$ nicotine-appropriate responding (ie the $\mathrm{ED}_{50}$ with $95 \%$ confidence intervals, expressed in $\mathrm{mg} /$ $\mathrm{kg}$ ) was calculated using nonlinear regression of individual data points.

\section{RESULTS}

\section{Dose Effect of Methylphenidate on Nicotine Self-Administration and Sucrose-Maintained Responding}

Figure 1 illustrates the dose effect of methylphenidate on nicotine self-administration using two different unit doses (left panel) and on sucrose-maintained responding (right panel). Baseline responding for nicotine was higher in rats earning a unit dose of $0.01 \mathrm{mg} / \mathrm{kg} /$ infusion than in rats earning a unit dose of $0.03 \mathrm{mg} / \mathrm{kg} /$ infusion. At the $0.03 \mathrm{mg} /$ $\mathrm{kg}$ /infusion unit dose, ANOVA revealed a significant main effect of methylphenidate dose $\left(\mathrm{F}_{4,25}=2.90, p<0.05\right)$. Post hoc tests indicated that 2.5 and $5 \mathrm{mg} / \mathrm{kg}$ of methylphenidate significantly increased the number of nicotine infusions

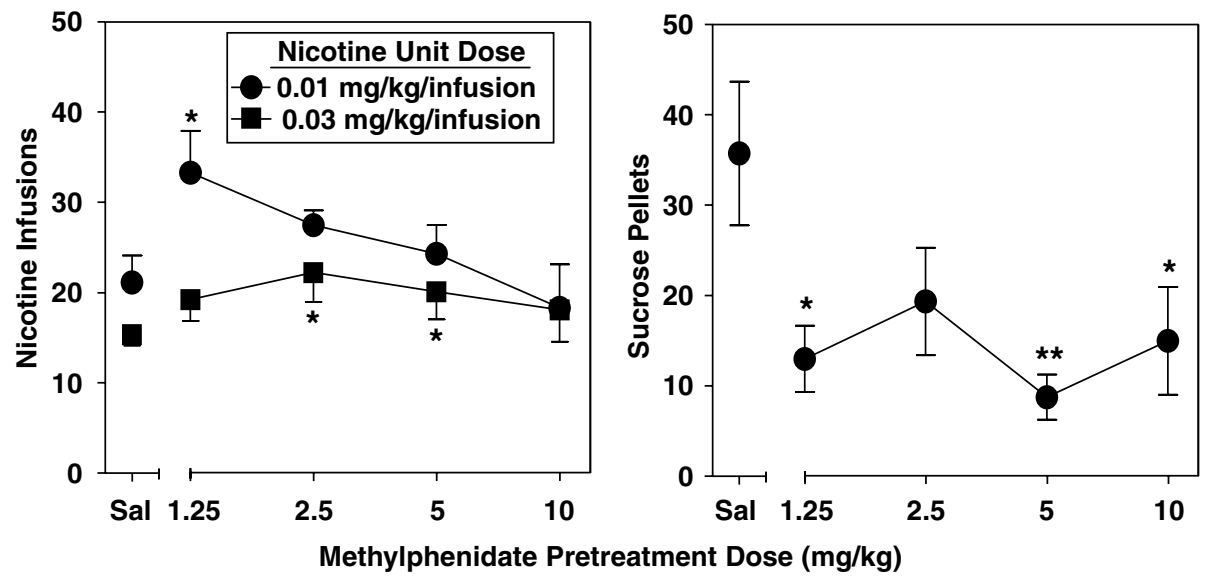

Figure I Dose effects of methylphenidate pretreatment on nicotine self-administration using two different unit doses (left panel; $n=7$ per group) and on sucrose-maintained responding (right panel; $n=8)$. Data points represent the mean $( \pm$ SEM) number of reinforcers earned per session as a function of methylphenidate pretreatment dose. *Indicates a significant difference from the effect of saline (Sal) on self-administration of the corresponding nicotine unit dose or on sucrose-maintained responding $(* p<0.05, * * p<0.0$ I) 
earned relative to saline pretreatment. At the $0.01 \mathrm{mg} / \mathrm{kg} /$ infusion unit dose, ANOVA revealed a significant main effect of methylphenidate dose $\left(\mathrm{F}_{4,25}=2.55, p<0.05\right)$. Post hoc tests indicated that $1.25 \mathrm{mg} / \mathrm{kg}$ of methylphenidate significantly increased the number of nicotine infusions earned relative to saline pretreatment. For sucrose-maintained responding, ANOVA revealed a significant main effect of methylphenidate dose $\left(\mathrm{F}_{4,28}=3.41, p<0.05\right)$. Post hoc tests indicated that pretreatment with $1.25,5$, and $10 \mathrm{mg} / \mathrm{kg}$ of methylphenidate significantly decreased the number of pellets earned relative to saline pretreatment.

\section{Effect of Repeated Methylphenidate on Nicotine Self-Administration}

Figure 2 illustrates the effect of repeated pretreatment with methylphenidate $(2.5 \mathrm{mg} / \mathrm{kg})$ on nicotine self-administration $(0.03 \mathrm{mg} / \mathrm{kg} /$ infusion $)$. A mixed-factor, repeatedmeasures ANOVA across all sessions (3 baseline, 12 pretreatment, 3 saline alone) revealed a significant pretreatment $\times$ day interaction $\left(\mathrm{F}_{17,204}=1.969 ; p<0.05\right)$, indicating that pretreatment with methylphenidate, but not saline, increased nicotine self-administration. The effect of repeated methylphenidate was subsequently assessed by conducting both within-subject and between-subject analyses. Post hoc within-subject comparisons indicated that methylphenidate-treated rats self-administered significantly more nicotine infusions on pretreatment days $1,2,3,5,6,7$, 8,9 , and 12 , as well as on the first saline pretreatment day (day 13), relative to their baseline levels. Post hoc withinsubject comparisons of saline-treated rats revealed a significant decrease in the number of nicotine infusions earned on pretreatment day 12, relative to their baseline levels. Post hoc between-group comparisons also indicated that methylphenidate-treated rats self-administered signi-

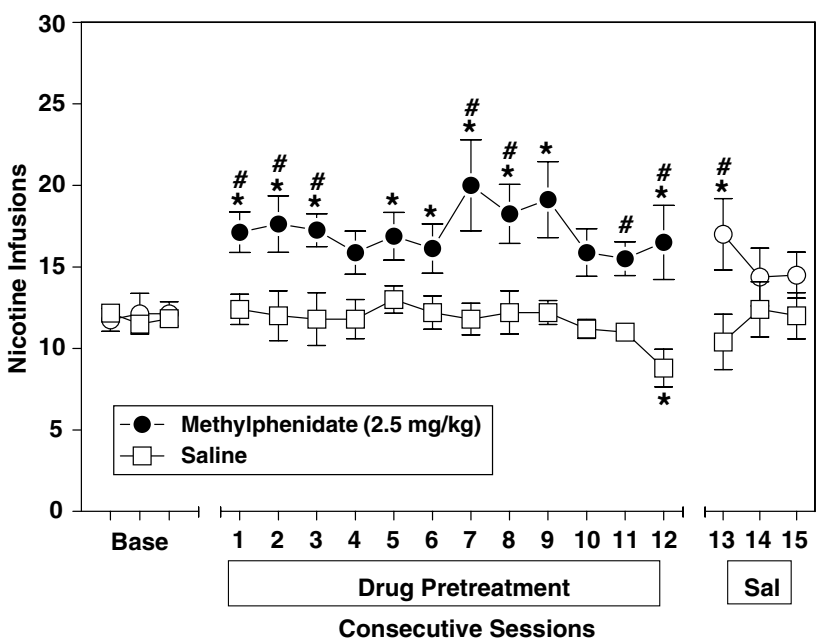

Figure 2 Effect of repeated pretreatment with methylphenidate $(2.5 \mathrm{mg} /$ $\mathrm{kg} ; n=8)$ or saline $(n=6)$ on nicotine self-administration at a unit dose of $0.03 \mathrm{mg} / \mathrm{kg} /$ infusion. Data points represent the mean $( \pm$ SEM) number of reinforcers earned across 3 baseline (Base), 12 drug pretreatment, and 3 saline (Sal) sessions. *Indicates a significant difference from the number of infusions earned during the respective final baseline session $(* p<0.0 \mathrm{I})$. \# Indicates a significant difference from the number of infusions earned by saline-treated rats on the corresponding session $\left({ }^{\#} p<0.0 \mathrm{I}\right)$. ficantly more nicotine infusions than saline-treated rats on pretreatment days $1,2,3,7,8,11$, and 12 , as well as on the first saline pretreatment day (day 13).

In order to examine whether the methylphenidateinduced increase in nicotine self-administration was due to a general increase in lever pressing, a mixed-factor, repeated-measures ANOVA was also conducted on the inactive lever response data (results not shown). This analysis revealed no significant main effects or interactions, indicating that the methylphenidate-induced increase in responding was specific to the active lever.

\section{Discriminative Stimulus Effects of Methylphenidate in Nicotine-Trained Rats}

Figure 3 illustrates the dose effects of nicotine (left panels) and methylphenidate, alone or in combination with nicotine (right panels), on responding in rats trained to discriminate nicotine from saline. In substitution testing, nicotine $(0.03-$ $0.3 \mathrm{mg} / \mathrm{kg}$ ) produced dose-dependent and full generalization, with an $\mathrm{ED}_{50}$ of $0.08(0.05-0.12) \mathrm{mg} / \mathrm{kg}$. The main effect of nicotine dose attained statistical significance $\left(\mathrm{F}_{5,35}=21.88, p<0.001\right)$, with post hoc tests indicating that $0.1,0.17$, and $0.3 \mathrm{mg} / \mathrm{kg}$ of nicotine elicited significantly greater nicotine-appropriate responding than saline control values; response rates were not disrupted significantly by any nicotine dose. Conversely, methylphenidate did not elicit nicotine-appropriate responding at any dose when administered alone. However, when methylphenidate was coadministered $5 \mathrm{~min}$ before a subthreshold dose of nicotine that did not elicit nicotine-appropriate responding by itself $(0.056 \mathrm{mg} / \mathrm{kg})$, a significant dose-dependent increase in responding on the nicotine-appropriate lever was obtained $\left(\mathrm{F}_{4,29}=5.50, p<0.01\right)$. Post hoc tests indicated that, relative to saline, significant increases in nicotineappropriate responding were obtained following administration of 5 and $10 \mathrm{mg} / \mathrm{kg}$ of methylphenidate in combination with $0.056 \mathrm{mg} / \mathrm{kg}$ of nicotine. Coadministration of nicotine with the 5 and $10 \mathrm{mg} / \mathrm{kg}$ doses of methylphenidate also produced significantly greater levels of nicotineappropriate responding relative to these doses alone. Response rates were not disrupted significantly by any methylphenidate dose, whether administered alone or in combination with nicotine.

\section{Effect of Repeated Nicotine on the Development of Methylphenidate Locomotor Sensitization}

Figure 4 illustrates the dose effect of repeated nicotine on locomotor activity. Across the repeated treatment phase, nicotine produced progressive increases in locomotor activity, an effect indicative of sensitization. A mixedfactor, repeated-measures ANOVA of these data revealed a significant nicotine dose $\times$ day interaction $\left(\mathrm{F}_{27,441}=11.07\right.$, $p<0.001)$. On day $1,0.8 \mathrm{mg} / \mathrm{kg}$ of nicotine produced significant hypoactivity relative to saline. Across treatment days, $0.4 \mathrm{mg} / \mathrm{kg}$ of nicotine produced a significant increase in activity by day 3 and all nicotine doses elicited a significant increase in locomotor activity on days 5-10 relative to saline.

Figure 5 illustrates the dose effect of repeated nicotine on subsequent challenge injections of either saline (upper 

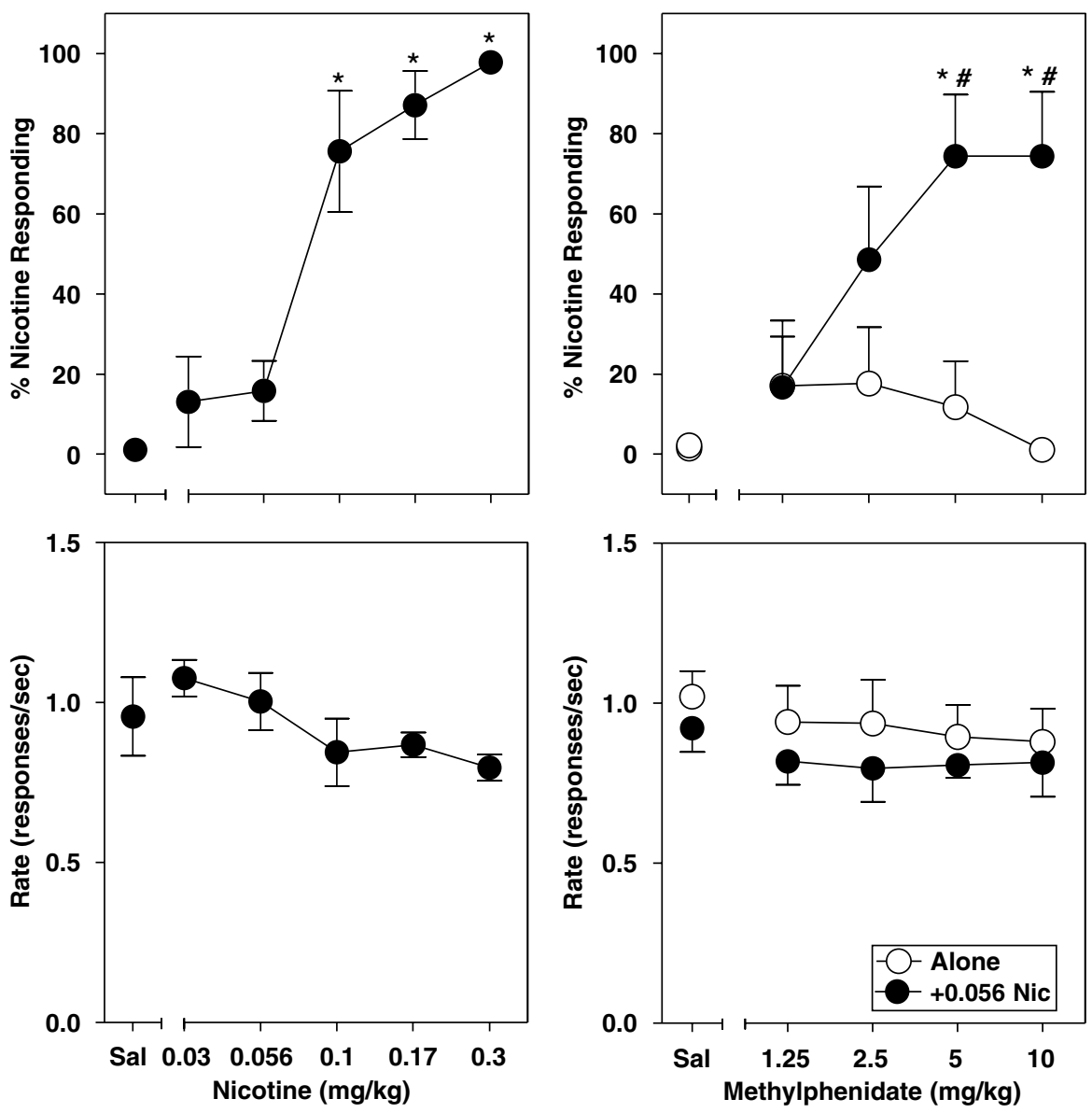

Figure 3 Discriminative stimulus and rate effects of nicotine $(0.03-0.3 \mathrm{mg} / \mathrm{kg}$, left panel) and methylphenidate $(1.25-10 \mathrm{mg} / \mathrm{kg}$, right panel) in rats $(n=6)$ trained to discriminate nicotine $(0.3 \mathrm{mg} / \mathrm{kg})$ from saline. Data points in the upper panels represent the mean ( \pm SEM) percentage of responses occurring on the nicotine-appropriate lever as a function of dose, whereas data points in the lower panels represent the mean ( \pm SEM) rate of responding (responses per second) as a function of dose. *Indicates a significant difference from the saline (Sal) control values $(* p<0.01)$. ${ }^{\#}$ Indicates a significant difference relative to the same methylphenidate dose given alone $\left({ }^{\#} p<0.05\right)$.

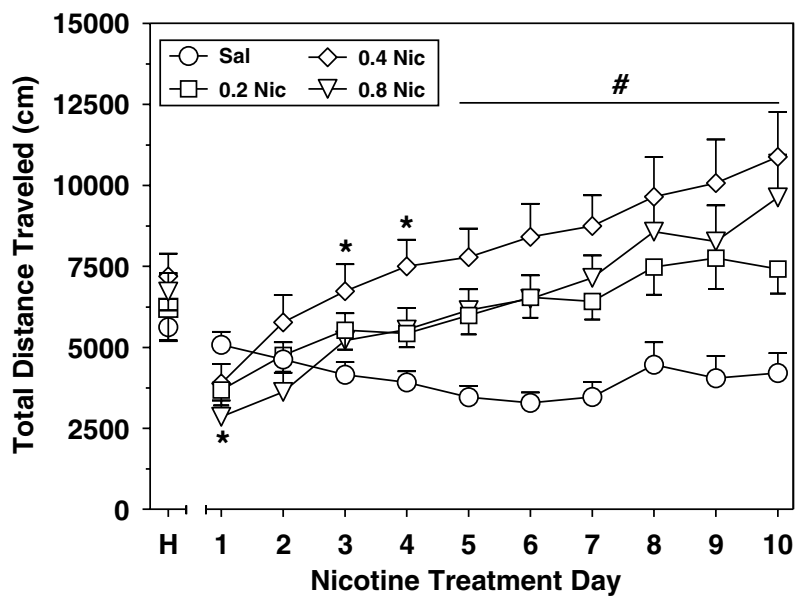

Figure 4 Dose effect of nicotine on locomotor activity across the 10-day repeated treatment phase $(n=16$ rats per dose). Rats were given I habituation day (designated as ' $\mathrm{H}$ ') before the 10 treatment days. Data are expressed as the mean $( \pm$ SEM) total distance traveled $(\mathrm{cm})$ per day. *Indicates a significant difference from the saline control value on the corresponding treatment day $(* p<0.01)$. "Indicates a significant difference from saline for each nicotine dose across days $5-10\left({ }^{\#} p<0.01\right)$. panel) or $2.5 \mathrm{mg} / \mathrm{kg}$ of methylphenidate (lower panel). A mixed-factor ANOVA (using prior nicotine treatment and challenge drug as between-subjects factors and challenge day as the within-subjects factor) revealed a significant challenge drug $\times$ day interaction $\left(F_{2,100}=9.3, p<0.001\right)$. Subsequent analysis of the saline challenge data indicated that prior nicotine treatment did not alter activity in response to saline on any challenge day. Analysis of the methylphenidate challenge data indicated that prior nicotine treatment also did not alter significantly the initial response to methylphenidate on day 1 . However, by day 3 , ANOVA revealed a significant main effect of prior nicotine treatment $\left(\mathrm{F}_{3,25}=4.02, p<0.05\right)$, indicating that exposure to nicotine promoted the induction of locomotor sensitization to methylphenidate. Post hoc Dunnett's tests indicated that rats treated previously with $0.8 \mathrm{mg} / \mathrm{kg}$ of nicotine exhibited significantly greater activity following methylphenidate relative to rats treated previously with saline $(p<0.01)$. To explore this latter finding further, the time course effect of methylphenidate on challenge days 1 and 3 in the rats treated previously with saline or nicotine $(0.8 \mathrm{mg} / \mathrm{kg})$ was compared (Figure 6); note that these data points reflect the 


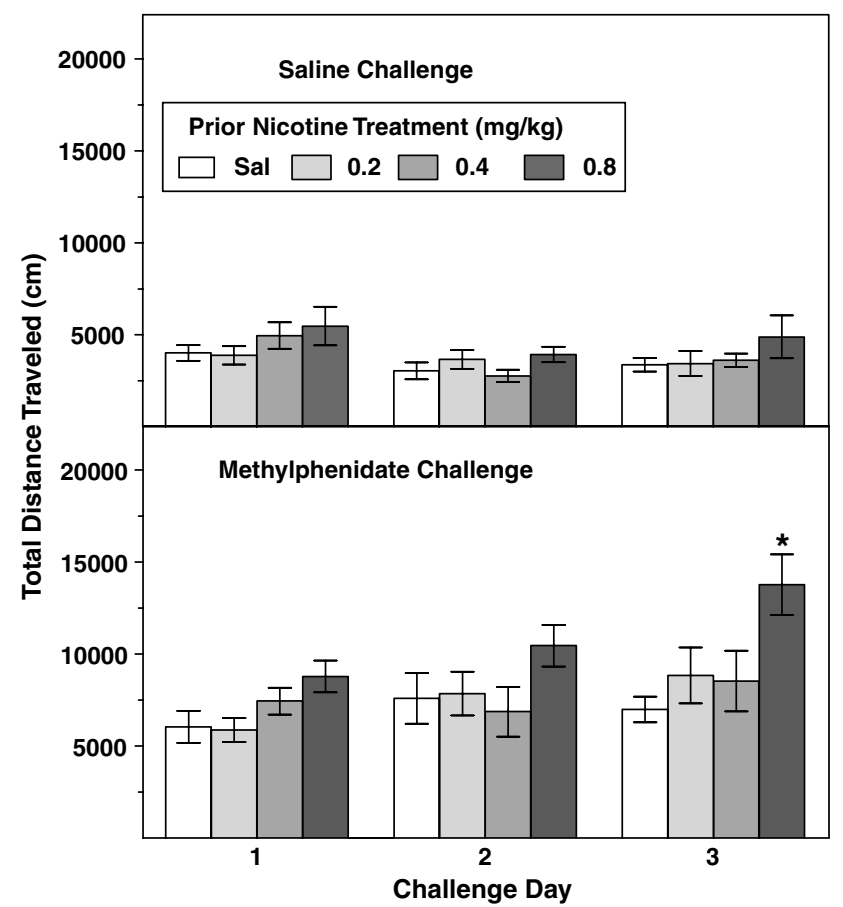

Figure 5 Effects of three consecutive challenge administrations of saline (upper panel) and methylphenidate $(2.5 \mathrm{mg} / \mathrm{kg}$; lower panel) on locomotor activity in separate groups of rats treated previously with nicotine $(0.2-$ $0.8 \mathrm{mg} / \mathrm{kg}$ ) or saline ( $n=8$ per group). Data are expressed as the mean $( \pm$ SEM) distance traveled $(\mathrm{cm})$ during each challenge day as a function of prior nicotine treatment dose. *Indicates a significant difference from the saline control value on the corresponding challenge day $(* p<0.05)$.

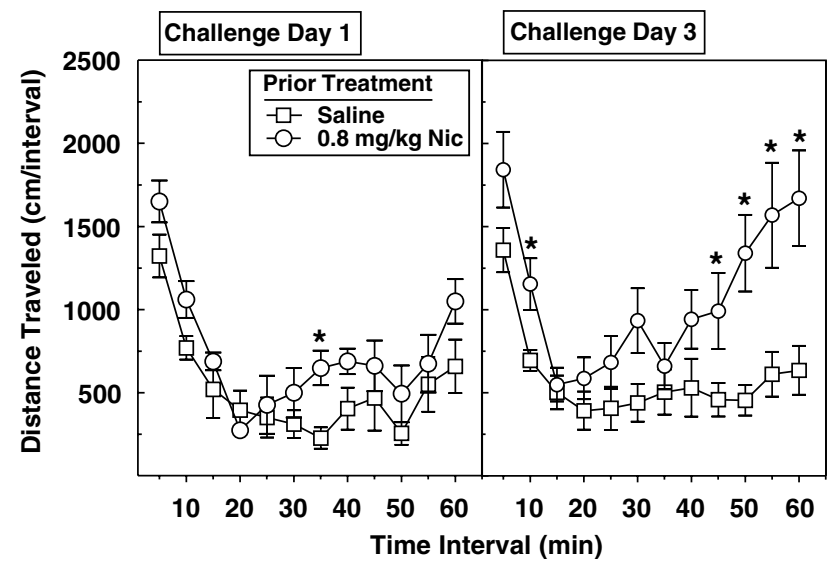

Figure 6 Time course effect of a challenge injection of methylphenidate $(2.5 \mathrm{mg} / \mathrm{kg})$ on day I (left panel) and day 3 (right panel) in rats treated previously with saline $(n=8)$ or nicotine $(0.8 \mathrm{mg} / \mathrm{kg} ; n=8)$. Data are expressed as the mean $( \pm$ SEM) distance traveled $(\mathrm{cm})$ during each 5 -min time interval. *Indicates a significant difference from saline-treated rats during the corresponding time interval $(* p<0.01)$.

time course effect of the total activity data of rats treated previously with saline and $0.8 \mathrm{mg} / \mathrm{kg}$ of nicotine during challenge days 1 and 3 presented in the lower portion of Figure 5. A mixed-factor ANOVA revealed a significant nicotine treatment $\times$ time interval $\times$ challenge day interaction, $\mathrm{F}_{11,132}=2.03, p<0.05$. Post hoc analysis indicated that, whereas nicotine-treated rats were significantly more active following methylphenidate at only the 35-min time point relative to saline-treated rats on day 1 (Figure 6, left panel), nicotine-treated rats were significantly more active at the 10 and 45-60 min time points on day 3 (Figure 6, right panel). Thus, although the data from day 1 provided little evidence of cross-sensitization to the initial methylphenidate challenge, prior exposure to $0.8 \mathrm{mg} / \mathrm{kg}$ of nicotine promoted the induction of sensitization following repeated methylphenidate injections.

\section{DISCUSSION}

The results of the present preclinical investigation demonstrate that methylphenidate enhances the abuse-related behavioral effects of nicotine in rats as assessed in the intravenous self-administration, drug discrimination, and locomotor cross-sensitization procedures. Acute pretreatment with methylphenidate $(1.25-10 \mathrm{mg} / \mathrm{kg})$ increased nicotine self-administration, although this effect differed depending on the nicotine unit dose available. In rats selfadministering a low unit dose of nicotine $(0.01 \mathrm{mg} / \mathrm{kg} /$ infusion), an increase in the number of infusions earned was obtained following pretreatment with $1.25 \mathrm{mg} / \mathrm{kg}$ of methylphenidate, but not following pretreatment with higher methylphenidate doses $(2.5-10 \mathrm{mg} / \mathrm{kg})$. In rats selfadministering a higher unit dose of nicotine $(0.03 \mathrm{mg} / \mathrm{kg} /$ infusion), an increase in the number of infusions earned was obtained only following 2.5 and $5 \mathrm{mg} / \mathrm{kg}$ of methylphenidate. These results indicate that as the unit dose of nicotine is increased, a greater pretreatment dose of methylphenidate is needed to enhance responding. However, since there were no differences in the effect of pretreatment with $10 \mathrm{mg} / \mathrm{kg}$ of methylphenidate between rats self-administering either nicotine unit dose, it is possible that high doses of stimulants can alter nicotine self-administration nonspecifically. While the precise rea$\operatorname{son}(\mathrm{s})$ for this biphasic pattern of results is unknown, Rauhut et al (2003) found similar biphasic dose effects of acute bupropion or methamphetamine pretreatment on nicotine self-administration in rats. Prada and Goldberg (1985) also reported that caffeine pretreatment increased nicotine self-administration in squirrel monkeys at low doses $(3-10 \mathrm{mg} / \mathrm{kg})$, while higher doses $(60-100 \mathrm{mg} / \mathrm{kg})$ decreased response rates. It is possible that the descending limb of the biphasic dose effect curve for stimulant drugs on nicotine self-administration is due to nonspecific behavioral impairment or to the induction of stereotypic behavior that is incompatible with lever pressing. Thus, the nonspecific effect of $10 \mathrm{mg} / \mathrm{kg}$ of methylphenidate may have masked the change in responding that normally occurs when the unit dose of nicotine is altered, thereby eliminating the difference between the two nicotine self-administration groups.

Interestingly, the dose-dependent increase in nicotine self-administration following acute methylphenidate did not appear to undergo tolerance, as repeated administration of $2.5 \mathrm{mg} / \mathrm{kg}$ of methylphenidate continued to increase selfadministration of nicotine $(0.03 \mathrm{mg} / \mathrm{kg} /$ infusion $)$ across 12 consecutive sessions. Nicotine self-administration returned to control levels across a subsequent 3-day period of saline 
administration, indicating that the effect of methylphenidate was reversible. The lack of tolerance to repeated methylphenidate is comparable to studies demonstrating that tolerance does not develop to the effects of repeated administration of bupropion on nicotine self-administration. Specifically, Shoaib et al (2003) demonstrated that repeated administration of $30 \mathrm{mg} / \mathrm{kg}$ of bupropion continued to increase nicotine self-administration across a 28-day treatment period and Rauhut et al (2005) reported that the acute decrease in nicotine self-administration produced by administration of $70 \mathrm{mg} / \mathrm{kg}$ of bupropion did not undergo tolerance across a 14-day treatment period.

Although these results indicate that low doses of methylphenidate can specifically increase nicotine selfadministration under an FR schedule of reinforcement, the exact mechanisms underlying this effect are not known. One potential interpretation is that methylphenidate attenuated the reinforcing effect of nicotine, thus leading to an increase in nicotine intake in an attempt to surmount the attenuation in reinforcing effectiveness (Yokel, 1987). However, given that prior work has demonstrated that selective nicotinic acetylcholine receptor antagonists such as mecamylamine and dihydro- $\beta$-erythriodine generally fail to increase nicotine self-administration (Corrigall and Coen, 1989; Watkins et al, 1999; but see Fattore et al (2002) for evidence of a mecamylamine-induced increase in nicotine self-administration), it seems unlikely that methylphenidate attenuated the reinforcing effect of nicotine. Although an FR schedule was used in the present study, assessing the effects of methylphenidate pretreatment on nicotine selfadministration under a PR schedule could help to clarify the mechanisms underlying the rate-increasing effect of methylphenidate on nicotine self-administration observed using an FR schedule (Arnold and Roberts, 1997; Richardson and Roberts, 1996). Alternatively, since nicotine infusions were signaled by illumination of cue lights, methylphenidate may have augmented the response to the visual stimuli known to play an important role in nicotine self-administration behavior in rats (Caggiula et al, 2001, 2002; Palmatier et al, 2006). Consistent with this notion, Files et al (1989) reported that methylphenidate (5-20 mg/ $\mathrm{kg}$ ) increased response rates during extinction (ie when food reinforcement was no longer available) if responding resulted in presentation of conditioned stimuli paired previously with food delivery, but not when responding occurred without the presentation of food-paired stimuli. Likewise, methylphenidate has been shown to selectively increase response rates maintained by a water-paired conditioned stimulus, while decreasing response rates in the absence of a water-paired stimulus (Robbins, 1978). Regardless of the interpretation, however, given that methylphenidate selectively increased responding for nicotine, but not sucrose, it appears that methylphenidate can differentially alter the incentive motivation for a drug and nondrug reinforcer. This conclusion parallels the recent clinical work of Rush et al (2005) showing that oral methylphenidate increases tobacco smoking in humans tested in a controlled laboratory environment, while decreasing food consumption.

To our knowledge, this is the first report to examine the discriminative stimulus effect of methylphenidate in nicotine-trained rats. Although nicotine produced dose- dependent substitution, methylphenidate did not elicit appreciable levels of nicotine-appropriate responding at any dose. However, when coadministered with a subthreshold dose of nicotine $(0.056 \mathrm{mg} / \mathrm{kg})$, methylphenidate produced a dose-dependent increase in nicotine-appropriate responding, although the maximal effect of methylphenidate did not meet criteria used traditionally for declaring full substitution (ie $\geqslant 80 \%$ nicotine-appropriate responding). This augmentation in the effect of a low nicotine dose by methylphenidate is similar to results reported by Gasior et al (2002), who examined the discriminative stimulus effects of caffeine in nicotine-trained rats. In that report, rats were trained to discriminate nicotine $(0.4 \mathrm{mg} / \mathrm{kg})$ from saline, and dose-effect curves were generated for nicotine and caffeine, both alone and in combination with a subthreshold dose of nicotine $(0.05 \mathrm{mg} / \mathrm{kg})$. Similar to the present results, caffeine administered alone did not elicit nicotine-appropriate responding at any dose; however, when combined with a low dose of nicotine, caffeine dose-dependently generalized to the nicotine cue (Gasior et al, 2002). The fact that methylphenidate did not substitute for nicotine when given alone contrasts with other reports showing that the discriminative stimulus effects of other classical stimulant drugs overlap, at least partially, with the nicotine cue. Bardo et al (1997) reported that nicotine substituted partially for D-amphetamine, and Desai et al (1999, 2003) reported that nicotine substituted fully for cocaine; in addition, both amphetamine and cocaine substitute partially for the nicotine cue (Mansbach et al, 1998). Regarding bupropion, some reports have found that bupropion substitutes partially (Desai et al, 2003) or fully (Wiley et al, 2002; Young and Glennon, 2002) for nicotine in generalization tests; however, a range of bupropion pretreatment doses failed to shift the nicotine dose-response curve (Shoaib et al, 2003), and mecamylamine pretreatment blocks the discriminative stimulus effects of nicotine, but not bupropion (Wiley et al, 2002). Thus, while the discriminative stimulus effects of nicotine and stimulant drugs, including methylphenidate, appear to overlap to some extent, there is sufficient evidence to conclude that the cues produced by these drugs are dissociable.

Consistent with other reports (Dwoskin et al, 1999; LeSage et al, 2006), the results of the locomotor activity experiment revealed that nicotine initially induced hypoactivity, followed by hyperactivity across repeated injections. More important, although there was little evidence indicative of cross-sensitization to the initial methylphenidate challenge following nicotine exposure, nicotine pre-exposure promoted the induction of locomotor sensitization following three repeated methylphenidate injections. The failure to find cross-sensitization between repeated nicotine and acute methylphenidate contrasts with evidence of crosssensitization between nicotine and other stimulant drugs. Nicotine pre-exposure enhances the subsequent locomotor stimulant effect of acute amphetamine (Birrell and Balfour, 1998), bupropion (Wilkinson et al, 2006), cocaine (Collins and Izenwasser, 2004), and methamphetamine (Kuribara, 1999). While the explanation for these dissociable effects among stimulants is not known, the nicotine-induced enhancement in locomotor sensitization with repeated methylphenidate indicates at least a partial overlap in the 
mechanisms underlying both nicotine and methylphenidate sensitization.

Although the present study does not address the neuropharmacological mechanisms underlying the interactive behavioral effects of methylphenidate and nicotine, it is possible that the mesolimbic dopamine pathway, a brain circuit implicated in drug reward (Bardo, 1998; Leshner and Koob, 1999; Wise, 1998), is involved. Nicotine increases dopaminergic neurotransmission by activation of highaffinity $\beta 2$ subunit-containing nicotinic cholinergic receptors localized on dopamine cell bodies in the ventral tegmental area (VTA), as well as by altering the tone of $\gamma$-amino butyric acid and glutamate inputs to the VTA (Mansvelder and McGehee, 2002; Mansvelder et al, 2003); the net effect is an increase in extracellular dopamine levels in the NAcc (Pontieri et al, 1996). In contrast, methylphenidate, a dopamine and norepinephrine transport inhibitor, does not release dopamine directly, but rather prevents dopamine clearance in the NAcc and other corticolimbic structures, thus yielding a net increase in extracellular dopamine in those terminal fields (Grace, 2001). As these mechanisms would suggest, it has been shown that coadministration of methylphenidate augments nicotineinduced increases in extracellular dopamine content in the NAcc (Gerasimov et al, 2000a,b), suggesting that the interactive effects of these drugs on mesolimbic dopamine transmission underlies the behavioral interactions noted in the present study. Regarding self-administration specifically, blockade of central dopamine receptors reduces nicotine self-administration (Corrigall and Coen, 1991; Corrigall et al, 1992), whereas administration of monoamine oxidase inhibitors or the dopamine reuptake inhibitor bupropion increases nicotine self-administration (Guillem et al, 2005, 2006; Rauhut et al, 2003). One caveat to this interpretation is that methylphenidate and bupropion are relatively nonselective inhibitors of the norepinephrine and dopamine transporters (Dwoskin et al, 2006; Han and $\mathrm{Gu}, 2006)$. While this suggests that both dopaminergic and noradrenergic mechanisms may be involved, a role for norepinephrine seems unlikely given that reboxetine, a selective norepinephrine uptake inhibitor, does not increase nicotine self-administration in rats (Rauhut et al, 2002). Thus, it appears that an enhanced response to nicotineevoked dopamine release in reward-relevant limbic terminal fields following methylphenidate administration may underlie the increase in nicotine self-administration.

Similarly, locomotor sensitization may also reflect alterations in dopamine transmission, as an enhanced dopamine response following repeated administration of psychostimulant drugs, including nicotine, is linked with the expression of behavioral sensitization (Benwell and Balfour, 1992; Pierce and Kalivas, 1997; Vezina, 2004). Interestingly, nicotine can augment dopamine transporter function (Middleton et al, 2004) and density (Harrod et al, 2004), suggesting that enduring nicotine-induced alterations in dopamine transporter function and/or density may play a role in the enhanced effect of repeated methylphenidate following nicotine treatment.

In drug discrimination, methylphenidate pretreatment may have also enhanced the discriminative stimulus effect of a low nicotine dose by enhancing the dopaminergic effect of nicotine. Caffeine, which augments extracellular dopa- mine levels, has been reported to potentiate the discriminative stimulus effect of a low nicotine dose (Gasior et al, 2002), suggesting that a similar mechanism may be implicated in the present drug discrimination results. However, evidence of a primary role for dopamine in mediating the nicotine cue is lacking, as selective dopamine antagonists generally fail to alter nicotine discrimination or attenuate nicotine discrimination only at doses that suppress response rates (Brioni et al, 1994; Corrigall and Coen, 1994; Le Foll et al, 2005). Since methylphenidate also elevates extracellular levels of acetylcholine in addition to dopamine (Tzavara et al, 2006), it may be that methylphenidate enhances nicotine's discriminative stimulus effects via a primarily nondopaminergic mechanism.

From a clinical perspective, it is interesting to note that methylphenidate (Ritalin ${ }^{\circledR}$ ) is the most commonly prescribed pharmacotherapy for attention-deficit/hyperactivity disorder (ADHD), a behavioral disorder characterized by excessive levels of activity, impulsivity, and inattention (Arnsten, 2006; Solanto et al, 2001; Volkow et al, 2005). Methylphenidate is an effective treatment for the behavioral and cognitive deficits associated with ADHD when administered orally at therapeutic doses (Greenhill, 2001; Volkow and Swanson, 2003; Biederman et al, 2004). Thus, one potential caveat of the present study is that methylphenidate was administered via subcutaneous injections, which may have produced a more rapid onset of action than orally administered methylphenidate as used in clinical settings. A study by Gerasimov et al (2000a,b) demonstrated that orally administered methylphenidate in rats is less potent in stimulating locomotor activity and increasing DA levels in the NAcc relative to the same methylphenidate doses administered via intraperitoneal injection; whether the same holds true for subcutaneous injections is yet to be determined. Another potential caveat is that the dose range of methylphenidate used in the present study included doses higher than those used clinically. Kuczenski and Segal (2005) advocated for the use of lower doses of methylphenidate (ie $\leqslant 3 \mathrm{mg} / \mathrm{kg}$ ) in preclinical studies in order to approximate clinically relevant plasma levels of methylphenidate. While some of the methylphenidate doses used in the present study (ie 5 and $10 \mathrm{mg} / \mathrm{kg}$ ) likely exceeded clinical doses, the lower doses evaluated (ie 1.25 and $2.5 \mathrm{mg} /$ $\mathrm{kg}$ ) are thought to fall within the therapeutic dose range. Importantly, these lower doses produced the greatest increase in nicotine self-administration, suggesting that the present results have clinical relevance.

In addition to the present results showing that methylphenidate alters the behavioral effects of nicotine in adult rats, developmental exposure to methylphenidate has been shown to alter the response to cocaine in adult rats. Administration of methylphenidate to periadolescent rats produces changes in subsequent cocaine self-administration (Brandon et al, 2001), cocaine-conditioned place preference (Andersen et al, 2002; Carlezon et al, 2003), and cocaineinduced hyperactivity (Torres-Reveron and Dow-Edwards, 2005) in adulthood. While the present findings demonstrate that methylphenidate can increase nicotine self-administration in adult rats, there is evidence that the behavioral effects of methylphenidate can differ between adolescent and adult rats (Andersen, 2005; Torres-Reveron and DowEdwards, 2005; Wooters et al, 2006). Since methylphenidate 
is commonly administered to children and adolescents in clinical settings, an important avenue for future research will be to determine the effects of developmental exposure to low doses of oral methylphenidate on subsequent acquisition of nicotine self-administration.

Individuals diagnosed with ADHD smoke cigarettes at a higher rate than the general population (Barkley et al, 1990; Kollins et al, 2005; Rohde et al, 2004). Although the exact reason(s) for this relationship is yet to be determined, one potential explanation is that tobacco smoking represents a form of self-medication in the ADHD population. Nicotine has comparable therapeutic effects to methylphenidate in adolescents (Potter and Newhouse, 2004) and adults (Connors et al, 1996; Levin et al, 2001) diagnosed with ADHD, raising the possibility that tobacco smoking in the ADHD population is maintained by the positive behavioral effects of nicotine. Alternatively, given the widespread exposure to methylphenidate in ADHD-diagnosed individuals, there has been interest in determining whether methylphenidate exposure increases the risk for smoking. In one prospective longitudinal study, Lambert and Hartsough (1998) reported that $93 \%$ of adult smokers diagnosed with ADHD during childhood who were treated with stimulants were daily smokers, compared to only $80 \%$ of ADHD-diagnosed smokers who were not treated previously with stimulant drugs. Moreover, methylphenidate has been shown to increase tobacco cigarette smoking in a controlled human laboratory experiment (Rush et al, 2005). The present preclinical results extend this previous work by providing evidence of a direct potentiating interaction between the abuse-related behavioral effects of methylphenidate and nicotine. Taken together, these results suggest that caution may be warranted when prescribing methylphenidate to cigarette smokers with ADHD.

\section{ACKNOWLEDGEMENTS}

We acknowledge the technical assistance provided by Joshua Cutshall, Laura Fenton, and Emily Geary. We also thank Dr Drake Morgan for helpful suggestions regarding the drug discrimination training procedure. During preparation of the manuscript, TE Wooters was supported by NIDA Predoctoral Training Grant T32 DA007304 and NM Neugebauer was supported by NIDA Predoctoral Training Grant T32 DA016176. Funding was provided by NIH Grant DA 017548.

\section{DISCLOSURE/CONFLICT OF INTEREST}

The authors do not have any conflict of interests (financial or otherwise) that might bias this work.

\section{REFERENCES}

Andersen SL (2005). Stimulants and the developing brain. Trends Pharmacol Sci 26: 237-243.

Andersen SL, Arvanitogiannis A, Pliakas AM, LeBlanc C, Carlezon Jr WA (2002). Altered responsiveness to cocaine in rats exposed to methylphenidate during development. Nat Neurosci 5: 13-14.

Arnold JM, Roberts DC (1997). A critique of fixed and progressive ratio schedules used to examine the neural substrates of drug reinforcement. Pharmacol Biochem Behav 57: 441-447.
Arnsten AF (2006). Stimulants: therapeutic actions in ADHD. Neuropsychopharmacology 31: 2376-2383.

Bardo MT (1998). Neuropharmacological mechanisms of drug reward: beyond dopamine in the nucleus accumbens. Crit Rev Neurobiol 12: 37-67.

Bardo MT, Bevins RA, Klebaur JE, Crooks PA, Dwoskin LP (1997). $(-)$-Nornicotine partially substitutes for (+)-amphetamine in a drug discrimination paradigm in rats. Pharmacol Biochem Behav 58: 1083-1087.

Bardo MT, Green TA, Crooks PA, Dwoskin LP (1999). Nornicotine is self-administered intravenously by rats. Psychopharmacology 146: $290-296$.

Barkley RA, Fischer M, Edelbrock CS, Smallish L (1990). The adolescent outcome of hyperactive children diagnosed by research criteria: I. An 8-year prospective follow-up study. J Am Acad Child Adolesc Psychiatry 29: 546-557.

Benwell ME, Balfour DJ (1992). The effects of acute and repeated nicotine treatment on nucleus accumbens dopamine and locomotor activity. Br J Pharmacol 105: 849-856.

Biederman J, Spencer T, Wilens T (2004). Evidence-based pharmacotherapy for attention-deficit hyperactivity disorder. Int J Neuropsychopharmacol 7: 77-97.

Birrell CE, Balfour DJ (1998). The influence of nicotine pretreatment on mesoaccumbens dopamine overflow and locomotor responses to D-amphetamine. Psychopharmacology 140: 142-149.

Brandon CL, Marinelli M, Baker LK, White FJ (2001). Enhanced reactivity and vulnerability to cocaine following methylphenidate treatment in adolescent rats. Neuropsychopharmacology 25 651-661.

Brioni JD, Kim DJ, O’Neill AB, Williams JE, Decker MW (1994). Clozapine attenuates the discriminative stimulus properties of (-)-nicotine. Brain Res 643: 1-9.

Caggiula AR, Donny EC, White AR, Chaudhri N, Booth S, Gharib MA et al (2001). Cue dependency of nicotine self-administration and smoking. Pharmacol Biochem Behav 70: 515-530.

Caggiula AR, Donny EC, White AR, Chaudhri N, Booth S, Gharib MA et al (2002). Environmental stimuli promote the acquisition of nicotine self-administration in rats. Psychopharmacology 163 230-237.

Carlezon Jr WA, Mague SD, Andersen SL (2003). Enduring behavioral effects of early exposure to methylphenidate in rats. Biol Psychiatry 54: 1330-1337.

Collins SL, Izenwasser S (2004). Chronic nicotine differentially alters cocaine-induced locomotor activity in adolescent $v s$ adult male and female rats. Neuropharmacology 46: 349-362.

Connors CK, Levin ED, Sparrow E, Hinton SC, Erhardt D, Meck WH et al (1996). Nicotine and attention in adult attention deficit hyperactivity disorder (ADHD). Psychopharmacol Bull 32: 67-73.

Corrigall WA, Coen KM (1989). Nicotine maintains robust selfadministration in rats on a limited-access schedule. Psychopharmacology 99: 473-478.

Corrigall WA, Coen KM (1991). Selective dopamine antagonists reduce nicotine self-administration. Psychopharmacology 104: 171-176.

Corrigall WA, Coen KM (1994). Dopamine mechanisms play at best a small role in the nicotine discriminative stimulus. Pharmacol Biochem Behav 48: 817-820.

Corrigall WA, Franklin KB, Coen KM, Clarke PB (1992). The mesolimbic dopaminergic system is implicated in the reinforcing effects of nicotine. Psychopharmacology 107: 285-289.

Cousins MS, Stamat HM, de Wit H (2001). Acute doses of $d$-amphetamine and bupropion increase cigarette smoking. Psychopharmacology 157: 243-253.

Desai RI, Barber DJ, Terry P (1999). Asymmetric generalization between the discriminative stimulus effects of nicotine and cocaine. Behav Pharmacol 10: 647-656. 
Desai RI, Barber DJ, Terry P (2003). Dopaminergic and cholinergic involvement in the discriminative stimulus effects of nicotine and cocaine in rats. Psychopharmacology 167: 335-343.

Dwoskin LP, Crooks PA, Teng L, Green TA, Bardo MT (1999). Acute and chronic effects of nornicotine on locomotor activity in rats: altered response to nicotine. Psychopharmacology 145: 442-451.

Dwoskin LP, Rauhut AS, King-Pospisil KA, Bardo MT (2006). Review of the pharmacology and clinical profile of bupropion, an antidepressant and tobacco use cessation agent. CNS Drug Rev 12: 178-207.

Fattore L, Cossu G, Martellotta MC, Fratta W (2002). Baclofen antagonizes intravenous self-administration of nicotine in mice and rats. Alcohol Alcohol 5: 495-498.

Files FJ, Branch MN, Clody D (1989). Effects of methylphenidate on responding under extinction in the presence and absence of conditioned reinforcement. Behav Pharmacol 1: 113-121.

Fowler JS, Logan J, Wang GJ, Volkow ND (2003). Monoamine oxidase and cigarette smoking. Neurotoxicology 24: 75-82.

Gasior M, Jaszyna M, Munzar P, Witkin JM, Goldberg SR (2002). Caffeine potentiates the discriminative-stimulus effects of nicotine in rats. Psychopharmacology 162: 385-395.

Gerasimov MR, Franceschi M, Volkow ND, Gifford A, Gatley SJ, Marsteller D et al (2000a). Comparison between intraperitoneal and oral methylphenidate administration: a microdialysis and locomotor study. J Pharmacol Exp Ther 295: 51-57.

Gerasimov MR, Franceschi M, Volkow ND, Rice O, Schiffer WK, Dewey SL (2000b). Synergistic interactions between nicotine and cocaine or methylphenidate depend on the dose of dopamine transporter inhibitor. Synapse 38: 432-437.

Grace AA (2001). Psychostimulant actions on dopamine and limbic system function: relevance to the pathophysiology and treatment of ADHD. In: Solanto MV, Arnsten AFT, Castellanos FX (eds). Stimulant Drugs and ADHD: Basic and Clinical Neuroscience. University Press: Oxford, pp 134-157.

Greenhill LL (2001). Clinical effects of stimulant medication in ADHD. In: Solanto MV, Arnsten AFT, Castellanos FX (eds). Stimulant Drugs and ADHD: Basic and Clinical Neuroscience. University Press: Oxford, pp 31-72.

Guillem K, Vouillac C, Azar MR, Parsons LH, Koob GF, Cador M et al (2005). Monoamine oxidase inhibition dramatically increases the motivation to self-administer nicotine in rats. $J$ Neurosci 25: 8593-8600.

Guillem K, Vouillac C, Azar MR, Parsons LH, Koob GF, Cador M et al (2006). Monoamine oxidase A rather than monoamine oxidase B inhibition increases nicotine reinforcement in rats. Eur J Neurosci 24: 3532-3540.

Han DD, Gu HH (2006). Comparison of the monoamine transporters from human and mouse in their sensitivities to psychostimulant drugs. BMC Pharmacol 6: 6.

Harrod SB, Mactutus CF, Bennett K, Hasselrot U, Wu G, Welch M et al (2004). Sex differences and repeated intravenous nicotine: behavioral sensitization and dopamine receptors. Pharmacol Biochem Behav 78: 581-592.

Henningfield JE, Griffiths RR (1981). Cigarette smoking and subjective response: effects of $d$-amphetamine. Clin Pharmacol Ther 30: 497-505.

Kollins SH, McClernon FJ, Fuemmeler BF (2005). Association between smoking and attention-deficit/hyperactivity disorder symptoms in a population-based sample of young adults. Arch Gen Psychiatry 62: 1142-1147.

Kuczenski R, Segal DS (2005). Stimulant actions in rodents: implications for attention-deficit/hyperactivity disorder treatment and potential stimulant abuse. Biol Psychiatry 57: 1391-1396.

Kuribara H (1999). Does nicotine modify the psychotoxic effect of methamphetamine? Assessment in terms of locomotor sensitization in mice. J Toxicol Sci 24: 55-62.
Lambert NM, Hartsough CS (1998). Prospective study of tobacco smoking and substance dependencies among samples of ADHD and non-ADHD participants. J Learn Disabil 31: 533-544.

Le Foll B, Sokoloff P, Stark H, Goldberg SR (2005). Dopamine D3 receptor ligands block nicotine-induced conditioned place preferences through a mechanism that does not involve discriminative-stimulus or antidepressant-like effects. Neuropsychopharmacology 30: 720-730.

LeSage MG, Gustaf E, Dufek MB, Pentel PR (2006). Effects of maternal intravenous nicotine administration on locomotor behavior in pre-weanling rats. Pharmacol Biochem Behav 85: 575-583.

Leshner AI, Koob GF (1999). Drugs of abuse and the brain. Proc Assoc Am Physicians 111: 99-108.

Levin ED, Connors CK, Silva D, Canu W, March J (2001). Effects of chronic nicotine and methylphenidate in adults with attention deficit/hyperactivity disorder. Exp Clin Psychopharmacol 9: 83-90.

Mansbach RS, Rovetti CC, Freedland CS (1998). The role of monoamine neurotransmitter systems in the nicotine discriminative stimulus. Drug Alcohol Depend 52: 125-134.

Mansvelder HD, De Rover M, McGehee DS, Brussaard AB (2003). Cholinergic modulation of dopaminergic reward areas: upstream and downstream targets of nicotine addiction. Eur J Pharmacol 480: $117-123$.

Mansvelder HD, McGehee DS (2002). Cellular and synaptic mechanisms of nicotine addiction. J Neurobiol 53: 606-617.

Middleton LS, Cass WA, Dwoskin LP (2004). Nicotinic receptor modulation of dopamine transporter function in rat striatum and medial prefrontal cortex. J Pharmacol Exp Ther 308: 367-377.

Palmatier MI, Evans-Martin FF, Hoffman A, Caggiula AR, Chaudhri N, Donny EC et al (2006). Dissociating the primary reinforcing and reinforcement-enhancing effects of nicotine using a rat self-administration paradigm with concurrently available drug and environmental reinforcers. Psychopharmacology 184: 391-400.

Paterson NE, Semenova S, Gasparini F, Markou A (2003). The mGluR5 antagonist MPEP decreased nicotine self-administration in rats and mice. Psychopharmacology 167: 257-264.

Pierce RC, Kalivas PW (1997). A circuitry model of the expression of behavioral sensitization to amphetamine-like psychostimulants. Brain Res Brain Res Rev 25: 192-216.

Pontieri FE, Tanda G, Orzi F, Di Chiara G (1996). Effects of nicotine on the nucleus accumbens and similarity to those of addictive drugs. Nature 382: 255-257.

Potter AS, Newhouse PA (2004). Effects of acute nicotine administration on behavioral inhibition in adolescents with attention-deficit/hyperactivity disorder. Psychopharmacology 176: $182-194$

Prada JA, Goldberg SR (1985). Effects of caffeine or nicotine pretreatments on nicotine self-administration by the squirrel monkey. Pharmacologist 27: 226.

Rauhut AS, Dwoskin LP, Bardo MT (2005). Tolerance does not develop to the decrease in nicotine self-administration produced by repeated bupropion administration. Nicotine Tob Res 7: 901-907.

Rauhut AS, Mullins SN, Dwoskin LP, Bardo MT (2002). Reboxetine: attenuation of nicotine self-administration in rats. J Pharm Exp Ther 303: 664-672.

Rauhut AS, Neugebauer N, Dwoskin LP, Bardo MT (2003). Effect of bupropion on nicotine self-administration in rats. Psychopharmacology 169: 1-9.

Richardson NR, Roberts DC (1996). Progressive ratio schedules in drug self-administration studies in rats: a method to evaluate reinforcing efficacy. J Neurosci Methods 66: 1-11.

Robbins TW (1978). The acquisition of responding with conditioned reinforcement: effects of pipradrol, methylphenidate, 
$d$-amphetamine and nomifensine. Psychopharmacology 58: 79-87.

Rohde P, Kahler CW, Lewinsohn PM, Brown RA (2004). Psychiatric disorders, familial factors, and cigarette smoking: III. Associations with cessation by young adulthood among daily smokers. Nicotine Tob Res 6: 509-522.

Rose JE, Levin ED (1991). Inter-relationships between conditioned and primary reinforcement in the maintenance of cigarette smoking. Br J Addict 86: 605-609.

Roll JM, Higgins ST, Tidey J (1997). Cocaine use can increase cigarette smoking: evidence from laboratory and naturalistic settings. Exp Clin Psychopharmacol 5: 263-268.

Rush CR, Higgins ST, Vansickel AR, Stoops WW, Lile JA, Glaser PE (2005). Methylphenidate increases cigarette smoking. Psychopharmacology 181: 781-789.

Schorling JB, Gutgesell M, Klas P, Smith D, Keller A (1994). Tobacco, alcohol and other drug use among college students. J Subst Abuse 6: 105-115.

Shoaib M, Sidhpura N, Shafait S (2003). Investigating the actions of bupropion on dependence-related effects of nicotine in rats. Psychopharmacology 165: 405-412.

Sigmon SC, Tidey JW, Badger GJ, Higgins ST (2003). Acute effects of $\mathrm{D}$-amphetamine on progressive-ratio performance maintained by cigarette smoking and money. Psychopharmacology 167: 393-402.

Solanto MV, Arnsten AFT, Castellanos FX (2001). Stimulant Drugs and ADHD: Basic and Clinical Neuroscience. University Press: Oxford, pp 134-157.

Tidey JW, O’Neill SC, Higgins ST (2000). D-Amphetamine increases choice of cigarette smoking over monetary reinforcement. Psychopharmacology 153: 85-92.

Torres-Reveron A, Dow-Edwards DL (2005). Repeated administration of methylphenidate in young, adolescent, and mature rats affects the response to cocaine later in adulthood. Psychopharmacology 181: 38-47.
Tzavara ET, Bymaster FP, Overshiner CD, Davis RJ, Perry KW, Wolff $\mathrm{M}$ et al (2006). Procholinergic and memory enhancing properties of the selective norepinephrine uptake inhibitor atomoxetine. Mol Psychiatry 11: 187-195.

Vezina P (2004). Sensitization of midbrain dopamine neuron reactivity and the self-administration of psychomotor stimulant drugs. Neurosci Biobehav Rev 27: 827-839.

Volkow ND, Swanson JM (2003). Variables that affect the clinical use and abuse of methylphenidate in the treatment of ADHD. Am J Psychiatry 160: 1909-1918.

Volkow ND, Wang GJ, Fowler JS, Ding YS (2005). Imaging the effects of methylphenidate on brain dopamine: new model on its therapeutic actions for attention-deficit/hyperactivity disorder. Biol Psychiatry 57: 1410-1415.

Watkins SS, Epping-Jordan MP, Koob GF, Markou A (1999). Blockade of nicotine self-administration with nicotinic antagonists in rats. Pharmacol Biochem Behav 62: 743-751.

Wiley JL, Lavecchia KL, Martin BR, Damaj MI (2002). Nicotine-like discriminative stimulus effects of bupropion in rats. Exp Clin Psychopharmacol 10: 129-135.

Wilkinson JL, Palmatier MI, Bevins RA (2006). Preexposure to nicotine alters the subsequent locomotor stimulant effects of bupropion in rats. Nicotine Tob Res 8: 141-146.

Wise RA (1998). Drug-activation of brain reward pathways. Drug Alcohol Depend 51: 13-22.

Wooters TE, Dwoskin LP, Bardo MT (2006). Age and sex differences in the locomotor effect of repeated methylphenidate in rats classified as high or low novelty responders. Psychopharmacology 188: 18-27.

Yokel RA (1987). Intravenous self-administration: response rates, the effects of pharmacological challenges, and drug preferences. In: Bozarth MA (ed). Methods of Assessing the Reinforcing Properties of Abused Drugs. Springer-Verlag: New York, pp 1-33.

Young R, Glennon RA (2002). Nicotine and bupropion share a similar discriminative stimulus effect. Eur J Pharmacol 443: $113-118$. 